\title{
SNP55, a new functional polymorphism of MDM2-P2 promoter, contributes to allele-specific expression of $M D M 2$ in endometrial cancers
}

\author{
Kanako Okamoto ${ }^{1}$, Ryosuke Tsunematsu ${ }^{1,5^{*}}$, Tomoko Tahira ${ }^{4}$, Kenzo Sonoda ${ }^{1}$, Kazuo Asanoma ${ }^{1}$, Hiroshi Yagi ${ }^{1}$, \\ Tomoko Yoneda', Kenshi Hayashi ${ }^{3}$, Norio Wake ${ }^{2}$ and Kiyoko Kato ${ }^{1}$
}

\begin{abstract}
Background: The functional single nucleotide polymorphism (SNP) in the MDM2 promoter region, SNP309, is known to be associated with various diseases, particularly cancer. Although many studies have been performed to demonstrate the mechanism of allele-specific expression (ASE) on SNP309, they have only utilized in vitro techniques. It is unknown whether ASE of MDM2 is ascribed solely to SNP309, in vivo.

Methods: We attempted to evaluate ASE of MDM2 in vivo using post-labeling followed by automated capillary electrophoresis under single-strand conformation polymorphism conditions. For measuring a quantitative difference, we utilized the SNPs on the exons of MDM2 as markers, the status of which was heterozygous in a large population. To address the cause of ASE beyond $20 \%$, we confirmed sequences of both MDM2-3'UTR and promoter regions. We assessed the SNP which might be the cause of ASE using biomolecular interaction analysis and luciferase assay.

Results: ASE beyond $20 \%$ was detected in endometrial cancers, but not in cancer-free endometria samples only when an SNP rs 1690916 was used as a marker. We suspected that this ASE in endometrial cancer was caused by the sequence heterogeneity in the MDM2-P2 promoter, and found a new functional polymorphism, which we labelled SNP55. There was no difference between cancer-free endometria and endometrial cancer samples neither for SNP55 genotype frequencies nor allele frequencies, and so, SNP55 alone does not affect endometrial cancer risk. The SNP55 status affected the DNA binding affinity of transcription factor Sp1 and nuclear factor kappa-B (NFkB). Transcriptional activity of the P2 promoter containing SNP55C was suppressed by NFKB p50 homodimers, but that of SNP55T was not. Only ASE-positive endometrial cancer samples displayed nuclear localization of NFKB p50.
\end{abstract}

Conclusions: Our findings suggest that both the SNP55 status and the NFKB p50 activity are important in the transcriptional regulation of MDM2 in endometrial cancers.

\section{Background}

Normal mammalian somatic cells have a limited lifespan. Cells are able to divide only a limited number of times, and then undergo senescence. If the cellular senescence system is impaired by an insult such as an epigenetic change or a somatic mutation normal cells acquire the ability to proliferate for an unlimited period (immortalization). This is an

\footnotetext{
* Correspondence: tsunematsu.ryosuke@ibusuki2.hosp.go.jp

'Department of Obstetrics and Gynecology, Graduate School of Medical Sciences, Kyushu University, 3-1-1 Maidashi, Higashi-ku, Fukuoka 812-8582, Japan

${ }^{5}$ Current address: Department of Obstetrics and Gynecology, National Hospital Organization Ibusuki Medical Center, 4145, Junicho, Ibusuki, Kagoshima 891-0498, Japan

Full list of author information is available at the end of the article
}

essential step that initiates tumorigenesis in the malignant transformation of normal cells [1-6]. Inheritable genome variations were also recently shown to disrupt cellular senescence system [7-9]. Genome wide association studies (GWAS) have revealed an association between genetic variations and common diseases, and that most of these polymorphisms do not change the protein sequence [10,11]. Some of the single nucleotide polymorphisms (SNPs) in gene promoter regions, termed rSNPs, have a potential to modulate gene expression.

If rSNP exists as a heterozygous state, a quantitative difference in gene expression between the two alleles should be observed. This phenomenon is called allele-specific expression (ASE) [12-20]. A previous study about ASE 
revealed that six out of 13 genes showed more than a $20 \%$ difference in gene expression between the two alleles [12]. Lo et al. [17] showed that ASE was detected in $54 \%$ of genes (326/602), which was investigated using Affymetrix ${ }^{\circ}$ HuSNP oligo array in the kidneys and livers from seven individuals; they also identified that most imbalanced expression was associated with autosomal genes and a few imprint genes. Another study detected ASE in $53 \%$ of genes (731/1389) in the leukocytes from 12 unrelated individuals, [19]. Many studies have confirmed the association between diseases, particularly cancer, and rSNPs in various autosomal genes [APC [9], TGFBR1 [21], AGTR1 [22], FSHB [23, 24], BRCA1 and BRCA2 [25], CRAC1 [26], CDH1 [27], MDM2 [28-30]].

$M d m 2$ was originally identified as an amplified protooncogene in the BALB/c cell line 3T3DM [31]. The major function of $\mathrm{Mdm} 2$ is a negative regulation of the p53 tumor suppressor protein. Mdm2 has E3 ubiquitin ligase activity; it binds to the transcriptional activation domain of p53 leading to proteasome-mediated degradation [3235]. Cloning of the human homolog of Mdm2 allowed the confirmation of the interaction with p53, which indicated that MDM2 contributes to tumorigenesis. MDM2 [GenBank: AF527840] is amplified in $30-40 \%$ of sarcomas [36, 37] as well as various cancers [38]. Several reports describe MDM2 overexpression in certain cancers without gene amplification, such as leukemia [39], melanoma [40, 41], and breast cancer [42, 43].

$M D M 2$ is transcribed from two promoters; the one that is upstream of exon 1 (the P1 promoter) and the other that is in intron 1 (the P2 promoter) [44-46]. The MDM2-P1 promoter works for basal transcription independently of $\mathrm{p} 53$, whereas the $M D M 2-\mathrm{P} 2$ promoter is considered to be inducible by $\mathrm{p} 53$. There is a difference in the 5 ' untranslated region (UTR) sequence between P1- and P2derived mRNAs. ASE was reported in both MDM2-P1 and MDM2-P2 promoters. C1797G (rs937282; C/G) polymorphism in the MDM2-P1 promoter may affect transcription by altering the binding affinity of CCAATenhancer-binding protein $(\mathrm{C} / \mathrm{EBP} \alpha)$ to the promoter. It is also associated with bladder cancer risk [29]. In the MDM2-P2 promoter, SNP285 (rs117039649; C/G) [30, 47, 48], SNP309 (rs2279744; G/T) [28, 49], and SNP344 (rs1196333; A/T) [50] were reported, of which SNP309 is particularly well investigated. SNP309G enhances MDM2 expression from the P2 promoter by increasing the binding affinity of the transcription factor Sp1. Therefore, a large number of retrospective analyses were conducted showing an association between SNP309G and cancer risk [51-56]. However, other studies have failed to confirm this association [57-61], and the results remain inconsistent for endometrial cancer [51, 62-66].

In this study, we attempted to confirm that ASE of $M D M 2$ occurs in vivo in cancer-free endometria and in endometrial cancer. We identified a new functional polymorphism, SNP55 (rs2870820; C/T), which causes ASE of MDM2. SNP55 status alone had no association with endometrial cancer risk. We revealed that SNP55C suppressed the transcriptional activity of the MDM2-P2 promoter by recruiting the nuclear factor kappa-B (NFkB) p50 homodimer.

\section{Methods}

\section{Tissue samples and cell culture}

The use of human tissue in this investigation was reviewed and approved by the ethical committee of Kyushu University. Cancer-free endometrial tissues $(n=45)$ were collected from hysterectomy specimens removed for the treatment of uterine myomas. Endometrial cancer samples $(n=45)$ were obtained from women who underwent surgery. In all case, written consent for tissue donation was obtained from participants. COS-1 cells were maintained in Dulbecco's modified Eagle's medium (DMEM) (Sigma) supplemented with $10 \%$ calf serum (Nichirei Biosciences) and $1 \%$ penicillin/streptomycin (Gibco). Cells were cultured at $37{ }^{\circ} \mathrm{C}$ in a humidified $5 \% \mathrm{CO}_{2}$ atmosphere.

\section{Preparation of genomic DNA, RNA, and CDNA}

Genomic DNA and RNA were concurrently extracted from endometrium specimens (both with cancer and cancer-free) using AllPrep DNA/RNA Mini Kit (Qiagen). An aliquot of the total RNA (500 ng) was reverse transcribed to cDNA using random primer and ReverTra Ace- $\alpha^{\circ}$ (Takara).

\section{Genotyping}

Both SNP55 and SNP309 in the MDM2-P2 promoter region were identified via PCR amplification followed by sequencing the amplified PCR fragments. PCR primers (Forward: 5' -CGAGCTTGGCTGCTTCTGGG-3', Reverse: 5'-GCTGGAATCTGTGAGGTGGT-3') were designed against the sequence around these two SNPs to amplify approximately $1 \mathrm{kbp}$ of the product using KODFX (TOYOBO). PCR products were separated by a $1 \%$ agarose gel and excised. They were purified using GEX ${ }^{\mathrm{TM}}$ PCR DNA and Gel Band Purification Kit (GE Healthcare). Purified PCR products were sequenced using a sequencing primer (5' -AGCAAGTCGGTGCTTACCTG-3'). Sequencing reactions were conducted using BigDye Terminator v3.1 Cycle Sequencing Kits (Applied Biosystems). Two marker SNPs, rs1690916 (A/G) and rs937283 (A/G), were genotyped by post-labeling followed by automated capillary electrophoresis (PLACE) under single-strand conformation polymorphism (SSCP) conditions (the PLACESSCP method) using genomic DNA. 
In order to determine the haplotype involving SNP55 and SNP309, we cloned the relevant region and sequenced. The MDM2-P2 promoter region of genomic DNA was amplified by PCR with KOD-FX (TOYOBO) using forward primer, 5'-TATCTCGAGGTACTGGCCCGGCAGCGA-3' and reverse primer, 5'-TATAAGCTTGAACACAGCTG GGAAAATGC-3'. PCR products were inserted into EcoRV site of pBluescript ${ }^{\circ}$ (Stratagene) and the insert regions were sequenced.

\section{PLACE-SSCP and in vitro transcription}

DNA fragments around marker SNPs were amplified by PCR. For marker SNP rs1690916, PCR amplification was performed using Ampli Taq DNA polymerase (Applied Biosystems) and the following primers: forward, $5^{\prime}$-attA TCAGGCCCTTTTTCACACA-3' and reverse, $5^{\prime}$ '-gttACC CAGGCCAAGAAGGTACT-3' (product size 122 bp). The "att" and "gtt" sequences were tags attached for the purpose of fluorescent post-labeling [67]. For marker SNP rs937283, PCR was performed using KOD-FX (TOYOBO) and the following primers: forward, 5 'attCTGGCCCGGAGAGTG GAAT-3' and reverse, 5' -gttAATGGTCCCGTTTTCGCG CTTGGAGTC-3' (product size 124 bp), and because the initial attempt revealed poor separation of the two alleles of SNP rs937283, we attached 9-bp extra-sequences (underlined) to the N-terminus of the reverse primer, so that only the PCR product from the G-allele of SNP rs937283 could form a stem-loop structure. The details of the PLACE-SSCP method have been described previously [67]. The analysis of marker SNP rs937283 was performed using $0.094 \mu \mathrm{l}$ of Thermo Sequenase (GE Healthcare) per sample for post-labeling, which was ten times greater than usual, and SSCP electrophoresis was performed at $42^{\circ} \mathrm{C}$.

Precise quantification of the alleles in cDNA was performed by synthesizing four RNA fragments corresponding to the two marker SNPs (A/G for rs937283 and G/A for rs1690916) by in vitro transcription. Templates were produced by PCR amplification using the same primers as those used for PLACE-SSCP. Templates were subcloned into $\mathrm{pBluescript}^{\circ}$ (Stratagene) and subjected to in vitro transcription using an in vitro transcription $\mathrm{T} 7$ kit (Takara). Template DNA was digested with DNase (Promega). Following phenol and chloroform extractions, the produced RNA was purified and concentration was measured by NanoDrop ${ }^{\text {Tw }}$ (Thermo Scientific).

\section{Transcription factor Sp1 and NFKB p50-DNA binding analysis}

Biomolecular interaction analysis (BIA) was performed on the Biacore3000 (GE Healthcare). Sensor chip SA was used to anchor one of the two different double-stranded DNA 22-mers (5'-GACGGTGTCCC/TTTCTATCGCTG-3') rep resenting the MDM2-P2 promoter with different SNP55 status, of which the N-terminus was biotinylated. To confirm that only double-stranded DNA fragments were immobilized, single-stranded binding proteins were injected at a concentration of $2.5 \mu \mathrm{g} / \mathrm{ml}$ with a flow $5 \mu \mathrm{l} / \mathrm{min}$ for $1 \mathrm{~min}$ and no signals were detected (data not shown). At a level of 2000 response units (RU), DNA fragments were immobilized in each flow cell. Transcription factor Sp1 (Proteinone), extracted from HeLa cells, or recombinant NFkB p50 (Enzo) was prepared at a concentration of $1 \mu \mathrm{g} / \mathrm{ml}$, in advance. Both proteins were injected in flow cells and a reference surface (blank) for comparison with a $5 \mu \mathrm{l} / \mathrm{min}$ flow for $5 \mathrm{~min}$ at $25{ }^{\circ} \mathrm{C}$. Biosensor data were analyzed using the BIA evaluation software.

\section{Construction of plasmids}

The MDM2-P2 promoter region of genomic DNA was amplified by PCR. PCR products containing either SNP55T or SNP55C were inserted in tandem into a pGL4 luciferase reporter plasmid (Promega). PCR of the MDM2-P2 promoter region was performed using the following primers: forward, 5'-TATCTCGAGGTACTGGCCCGGCAGCGA$3^{\prime}$ and reverse, 5' -TATAAGCTTGAACACAGCTGGGAA AATGC-3', including the XhoI and HindIII restriction site. We confirmed that the clones had different SNP55 statuses only, and that the other sequences were identical. We constructed expression vectors, pcDNA-myc-Sp1 and pcDNA-FLAG-NFkB p50, as follows. Transcription factor $\mathrm{Sp} 1$ and $\mathrm{NF}_{\mathrm{K} B} \mathrm{p} 50$ were amplified from the cDNA of MCF-7 cell lines by KOD-FX (TOYOBO). During PCR, we attached a myc-tag to the N-terminus of transcription factor $\mathrm{Sp} 1$ using the following primers: forward, 5'-TATGAATTCGCCACCATGGAACAGAA ACTGATCTCTGAAGAAGACCTGAGCGACCAAGA TCACTCC-3' and reverse, 5'-ATACTCGAGgTCAGA AGCCATTGCCACTGAT-3' and the FLAG tag to the $\mathrm{N}$-terminus of $\mathrm{NF \kappa B}$ p50 using the following primers: forward, 5' -TATGAATTCGCCACCATGGACTACAAA AGACGATGACGACAAGGCAGAAGATGATCCATAT$3^{\prime}$ and reverse, $5^{\prime}$-ATACTCGAGCTAACTTCCAGTGCC CCCTCC-3', including the EcoRI and XhoI restriction site. The amplified fragments and pcDNA3 (Invitrogen) were ligated using the EcoRI and XhoI enzymes (Takara Biotech $\mathrm{Co})$ and were subcloned into pcDNA3.

\section{Transfection and luciferase assay}

COS- 1 cells $\left(2 \times 10^{5}\right.$ cells $/ 6$ wells $)$ were transfected with $1 \mu \mathrm{g}$ of pGL4 reporter plasmids using Lipofectamine 2000 (Invitrogen) according to the manufacturer's instructions. Reporter plasmids and expression vectors were co-transfected (Fig. 6). Cells were harvested $24 \mathrm{~h}$ after transfection. Luciferase activity was determined using the Luciferase Assay System (Promega). For correction of variations, the cultured cells were cotransfected with a $\beta$-galactosidase expression vector, 


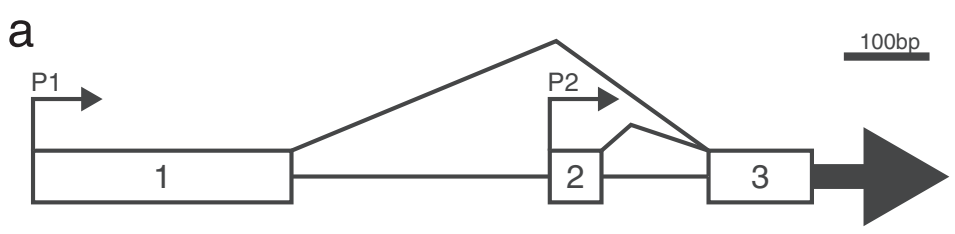

b

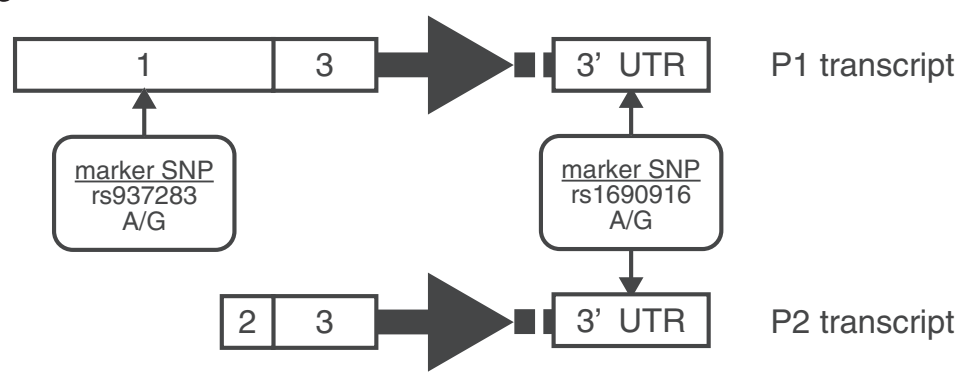

Fig. 1 Genomic organization of the human MDM2 gene. (a) The transcription start sites of the two promoters are indicated. (b) The two transcriptional products from the P1 and P2 promoters have different 5' (untranslated region) UTR sequences. All MDM2 RNAs have the same $3^{\prime}$ UTR sequences, in which single nucleotide polymorphism (SNP) rs1690916 is located. SNP rs937283 is on exon 1 , therefore only transcripts from the P1 promoter include this SNP

pcDNA-LacZ. Luciferase activity was normalized according to the $\beta$-galactosidase activity. Each transfection was performed in triplicate.

\section{Western blot analysis}

Cell extracts were prepared using an ice-cold lysis buffer (50 mM Tris-HCl [pH7.6], $300 \mathrm{mM} \mathrm{NaCl}, 0.5 \%$ Triton$\mathrm{X}, 400 \mu \mathrm{M} \mathrm{Na} \mathrm{NO}_{4}, 400 \mu \mathrm{M}$ EDTA, $10 \mathrm{mM} \mathrm{NaF}$, $10 \mathrm{mM}$ Na pyrophosphate, $10 \mu \mathrm{g} / \mathrm{ml}$ Aprotinin, $10 \mu \mathrm{g} /$ $\mathrm{ml}$ Leupeptin, $10 \mathrm{mM}$ lodoacetamide, and $1 \mathrm{mM}$ PMSF) for $15 \mathrm{~min}$. Protein concentrations were measured by Protein Assay (Bio-rad). An equal amount of cell lysate was separated by sodium dodecyl sulfate polyacrylamide gel electrophoresis (SDS-PAGE) (10 \% gel). Proteins were then transferred to polyvinylidene difluoride membranes (GE Healthcare). To avoid nonspecific binding, the membranes were incubated for $1 \mathrm{~h}$ at room temperature with tris-buffered saline (TBS) containing $0.05 \%$ Tween-20 and $5 \%$ nonfat dry milk, before being probed by respective antibodies. The primary antibodies used were transcription factor $\mathrm{Sp} 1, \mathrm{NF} \mathrm{B}$ p50, and glyceraldehyde 3-phosphate dehydrogenase (GAPDH; Santa Cruz Biotechnology). After washing in TBS containing $0.05 \%$ Tween-20, the membranes were incubated with the secondary antibodies, anti-mouse or anti-rabbit horseradish peroxidase (HRP) (Promega). Chemiluminescence was visualized using the Clarity Western ECL substrate (Bio-rad).

\section{Immunohistochemistry}

Immunohistochemical staining of NFkB p65 and p50 were performed on four endometrial cancer sections (two sections were ASE-positive and the other two were ASE-negative) as follows. For pretreatment, sections were blocked by the Protein block (Dako) for $10 \mathrm{~min}$ at room temperature and incubated overnight at $4{ }^{\circ} \mathrm{C}$ with the primary antibodies, p65 (1:100) and p50 (1:100) (Santa Cruz Biotechnology) diluted in antibody diluent (Dako). Endogenous peroxidase was inactivated using $3 \%$ hydrogen peroxidase (Sigma). The primary antibody in control experiments was replaced with normal goat IgG (Santa Cruz Biotechnology). After incubation with Envision $^{\text {Tix }}+$ Rabbit/HRP (Dako) for 30 min, signals were developed using 3.3-diaminobenzidine (DAB). The sections were then counterstained with hematoxylin and mounted.

\section{Statistical analysis}

Differences between two groups were evaluated using the Student $t$ test. The genotype frequencies and allele frequencies were compared using Fisher's exact test. The $P$-values given were two-sided and a $P$-value of $₫ 0.05$ was considered statistically significant.

\section{Results}

Selection of marker SNPs and optimization of PLACE-SSCP The SSCP method is sensitive for detecting single base sequence differences in PCR-amplified DNA fragments as separated peaks in electrophoretic analysis, whereas the subsequent development of PLACE-SSCP is suitable for precise estimation of SNP-allele frequency when applied to pooled DNA [67]. Here, we attempted to utilize the PLACE-SSCP method for evaluating ASE. To distinguish mRNAs produced from two alleles and measure a 
a

marker SNP

(rs1690916)

A / A

G / G

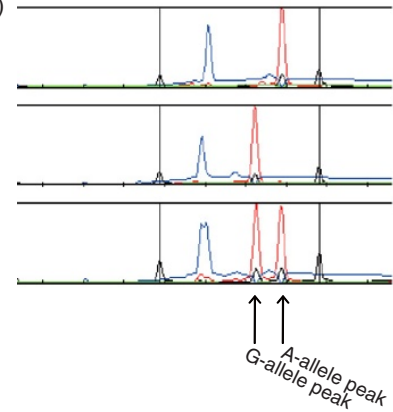

C

rs1690916

cDNA ratio

( $G$ allele : A allele)

$0: 1$

e)

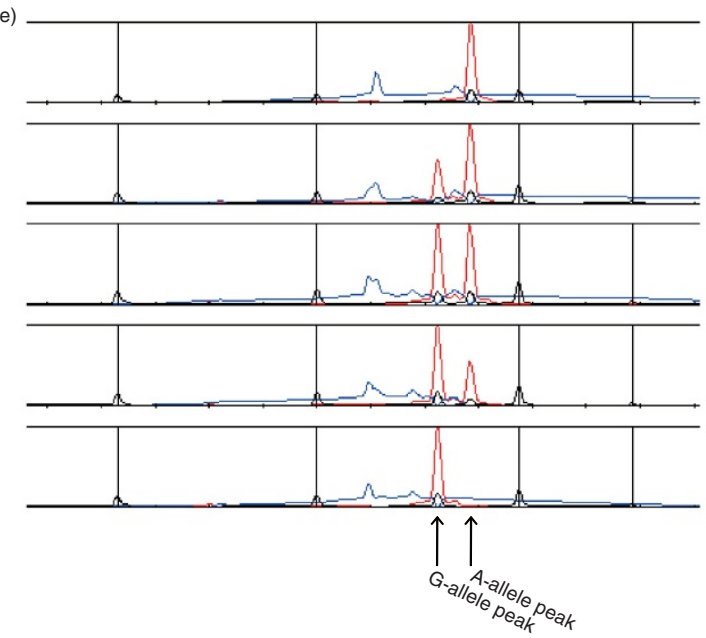

d

rs937283

cDNA ratio

(G allele : A allele)

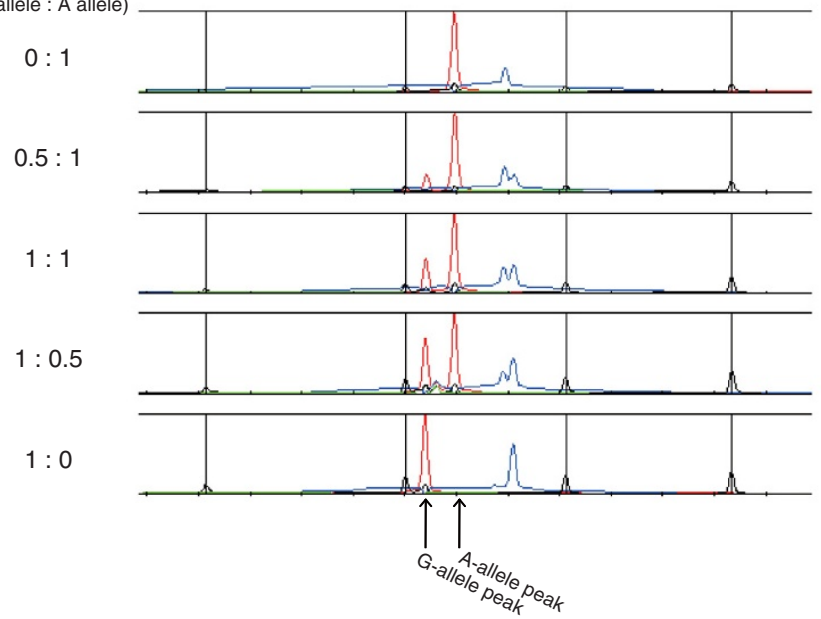

$1: 0$ b

marker SNP

(rs937283)

A / A

$G / G$

A / G

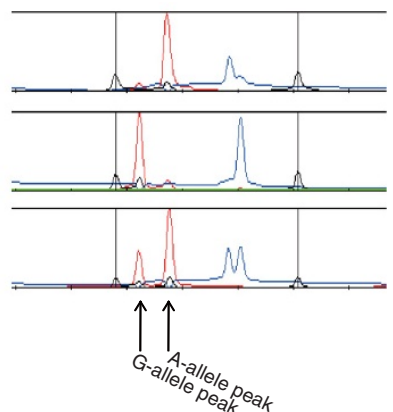

(G-peak height / A-peak ratio)

1.00

1.78

fluorescence signal ratio (A-peak height / G-peak ratio)

4.35

2.27

1.43

Fig. 2 (See legend on next page.) 
(See figure on previous page.)

Fig. 2 Application of PLACE-SSCP methods for the evaluation of ASE. a, d Genotyping marker single nucleotide polymorphism (SNP) rs1690916 (a) and rs937283 (b) by genomic DNA from cancer-free endometria. c, d Confirmation of precise measurement by PLACE-SSCP with marker SNP rs1690916 (c) and rs937283 (d) cDNA. RNA was transcribed in vitro and reverse-transcribed. The mixture rate between each allele is shown on the left

quantitative difference, we utilized the SNPs on the exons of $M D M 2$ as markers, the status of which was heterozygous in a large population. Because SNP rs1690916 is located at the 3'UTR of MDM2, it was used to detect ASE in the MDM2 total mRNA. We selected SNP rs937283, located at exon 1 of $M D M 2$, as another candidate marker SNP. Using SNP rs937283 as a marker, we can measure only the quantitative differences in mRNAs produced from the MDM2-P1 promoter (Fig. 1a, b). At first, we confirmed whether each marker SNP status was detectable by genomic DNA (Fig. 2a, b). Initial experiments revealed poor separation of the two alleles of SNP rs937283 (data not shown). Clean separation, with two fluorescent signal peaks, was achieved by attaching a short complementary sequence to the Gallele marker of SNP rs937283 at the 5' position.

We also noted that the fluorescence signal ratio of two alleles of SNP rs937283 was not close to 1.0 in cancerfree heterozygous samples. To precisely quantitate the expression of the two alleles in cDNA, via in vitro transcription we created two RNA fragment patterns in which only the marker SNP status was different. We then made an equal concentration mixture of these artificial RNAs and reverse-transcribed them to cDNA. PLACE-SSCP using these cDNA demonstrated equal expression levels of cDNA from heterozygote of cancerfree samples (Fig. 2c, d).

\section{ASE was detected in endometrial cancers, but not in cancer-free endometria}

We genotyped the marker SNPs in cancer-free endometria $(n=45)$ and identified heterozygous SNP rs937283 $(n=23)$ and SNP rs1690916 $(n=23$; Tables 1 and 2$)$. Their genomic DNA and cDNA were analyzed by PLACE-SSCP. The fluorescence signal ratio of each allele (SNP rs1690916: G-peak height A-peak height, SNP

Table 1 Genotype of marker SNP rs1690916 in samples of cancer-free endometria and endometrial cancer

\begin{tabular}{lll}
\hline $\begin{array}{l}\text { 3'UTR marker SNP } \\
\text { rs1690916 }\end{array}$ & $\begin{array}{l}\text { Cancer-free } \\
\text { endometria }\end{array}$ & $\begin{array}{l}\text { Endometrial cancer } \\
\text { (EMCA) }\end{array}$ \\
\hline A/A & 4 & 6 \\
A/G & 23 & 20 \\
G/G & 18 & 19 \\
total & 45 & 45 \\
\hline
\end{tabular}

rs937283: A-peak height/G-peak height) was used to evaluate ASE and we could accurately measure quantitative differences between the two alleles (Fig. 2c, d). At SNP rs1690916, the ratio in cDNA from all 23 measured cancer- free endometria was similar, and no significant difference (more than $20 \%$ ) was detected between allelic ratios in genomic DNA and cDNA of each sample (Fig. 3a). Yan and colleagues employed the threshold of the $20 \%$ relative difference to evaluate ASE [12]. Next, we observed ASE using SNP rs937283, but ASE from the MDM2-P1 promoter was not identified (Fig. 3c).

We applied the same methods to endometrial cancer samples. Of the total 45 endometrial cancer patients, 20 showed heterozygous SNP rs1690916 and SNP rs937283 (Tables 1 and 2, respectively). Three endometrial cancer samples (EMCA-19, 27, 34) represented mono-allelic amplification; thus, they were excluded from the ASE evaluation. ASE beyond $20 \%$ at marker SNP rs1690916 was observed in 2 of 17 heterozygous specimens (Fig. 3b). With regard to the cancer-free individuals, we attempted to examine ASE at SNP rs937283 but were unable to detect expression differences of more than $20 \%$ in all samples that were heterozygous for this marker SNP (Fig. 3d).

\section{ASE in endometrial cancer is associated with a new functional SNP}

ASE was not identified in endometrial cancer samples using marker SNP rs937283, suggesting that expression differences between alleles did not originate from the MDM2-P1 promoter. Thus, it was assumed that there are two possible mechanisms of generating quantitative differences from each allele, degradation of mRNA or different transcription levels (more/less) between alleles. To address the cause of ASE in endometrial cancer, we assessed these two hypotheses. We checked the former hypothesis by confirming the 3'

Table 2 Genotype of marker SNP rs937283 in samples of cancer-free endometria and endometrial cancer

\begin{tabular}{lll}
\hline $\begin{array}{l}\text { Exon1 marker SNP } \\
\text { rs937283 }\end{array}$ & $\begin{array}{l}\text { Cancer-free } \\
\text { endometria }\end{array}$ & $\begin{array}{l}\text { Endometrial cancer } \\
\text { (EMCA) }\end{array}$ \\
\hline A/A & 18 & 19 \\
A/G & 23 & 20 \\
G/G & 4 & 6 \\
total & 45 & 45 \\
\hline
\end{tabular}




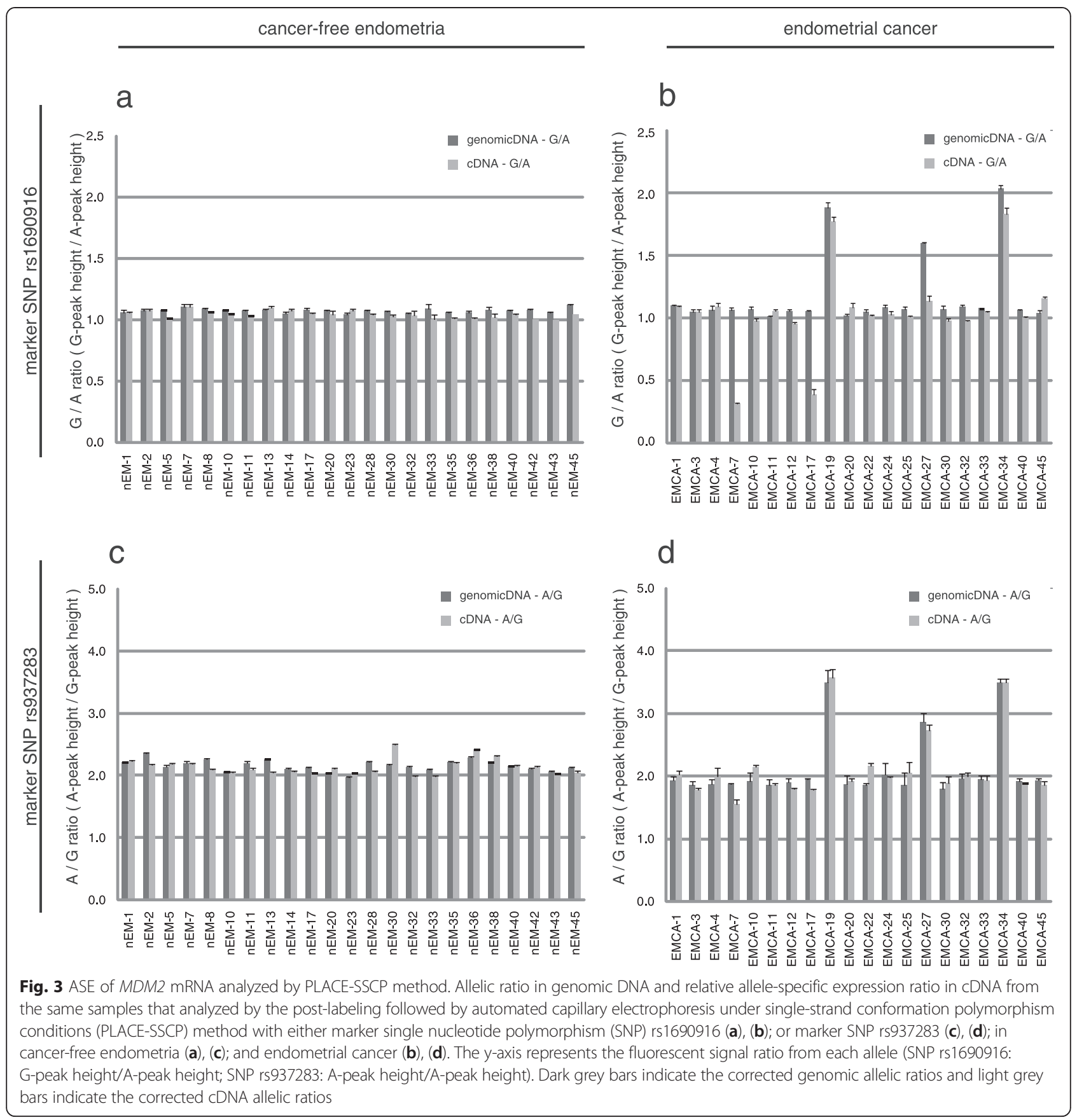

UTR sequences of two ASE-positive samples; however, we identified no genomic variations that affected the stability of transcribed mRNA, such as consensus sequences of microRNAs.

To examine the latter hypothesis, we checked MDM2P2 promoter sequences. In two ASE-positive individuals with endometrial cancer, one had $\mathrm{T} / \mathrm{T}$ and the other had T/G at SNP309. SNP55 (rs2870820) was also heterozygous (Fig. 4a).
We genotyped both SNP55 and SNP309 status in both cancer-free endometria $(n=45)$ and endometrial cancer samples $(n=45)$ analyzed by genome DNA sequencing (Table 3). Both genotype frequencies were found to be consistent with the Hardy-Weinberg's equilibrium. There was no difference between cancerfree endometria and endometrial cancer samples neither for the genotype frequencies, nor allele frequencies (Table 4). We then investigated the haplotype 
a

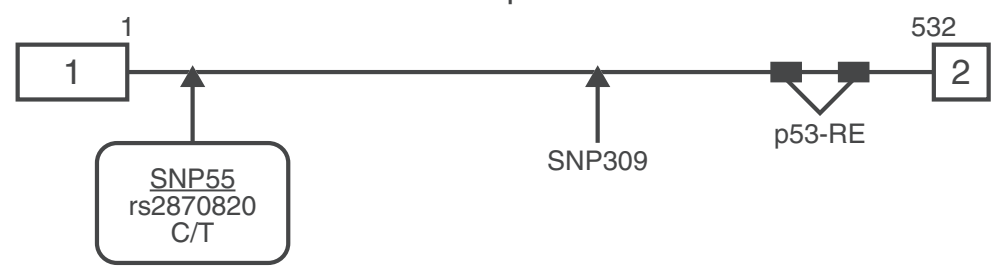

b

C-allele tCTGACGgtGTCCCCtCTATCGCtGGTG

$\frac{\mathrm{Sp} 1}{\mathrm{NFKB}}$

(Alibaba 2.1)

Fig. 4 MDM2-P2 promoter contains a SNP which affects the binding affinity of transcription factors. a Schematic illustration of the MDM2-P2 promoter. Single nucleotide polymorphism (SNP) 55 is upstream of SNP309 and two p53 responsive elements. b SNP55 alters transcription factors that can bind to DNA around SNP55 (analyzed by Alibaba 2.1)

frequency of the region involving SNP55 and SNP309 in cancer-free endometria. Frequency of each haplotype is as follows: $(55 \mathrm{C}-309 \mathrm{~T})=0.178$; $(55 \mathrm{C}-309 \mathrm{G})=0.467$; $(55 \mathrm{~T}-309 \mathrm{~T})=0.356$; $(55 \mathrm{~T}-309 \mathrm{G})=0.000$. Linkage disequilibrium $\left(\mathrm{r}^{2}\right)$ between SNP55 and SNP309 was calculated as 0.483 from these haplotype frequencies.

\section{The effect of SNP55 on the binding affinity of transcription factors to the MDM2-P2 promoter region}

To investigate the effect of SNP55 on the MDM2-P2 promoter transcriptional activation, we utilized a computer algorithm (Alibaba 2.1) and found that both the SNP55T and SNP55C alleles could bind transcription factor Sp1, but that only SNP55C had consensus sequence to NFkB (Fig. 4b). This result indicated that the SNP55 status may affect the binding affinity of transcription factor Sp1 and NFkB. To confirm the hypothesis, we conducted BIA. We focused on the p50 transcription factor, from the NFkB/Rel family, because both transcription factor $\mathrm{Sp} 1$ and $\mathrm{NF} \mathrm{B}$ p50 recognized the same DNA binding site and functionally interfere with each other [68]. Transcription factor Sp1 bound, insignificantly, but more easily to SNP55T than SNP55C (Fig. 5a, b). On the other hand, $\mathrm{NF} \mathrm{KB}$ p50 significantly generated more DNA-protein complexes with SNP55C (Fig. 5c, d; P $<0.05)$. These results indicate that the SNP55 status may affect the transcription activity of the MDM2-P2 promoter.

Only the SNP55C allele was suppressed by NFKB p50 in a dose-dependent manner

To evaluate the effect of the SNP55 status on MDM2-P2 promoter activity, we attempted a luciferase assay.
When the Sp1 expression vector and either SNP55T or SNP55C reporter plasmid were co-transfected with COS-1 cells, a slightly higher luciferase activity was detected with SNP55T compared with SNP55C (Fig. 6a). Next, we tested the functional interference between transcription factor Sp1 and NFkB p50 at the SNP55 site. In addition to the first luciferase experiment, we co-transfected a gradually increased amount of the NFkB p50 expression vector (0-0.8 $\mu \mathrm{g}$; Fig. 6b), and found that activity of MDM2-P2 promoter with SNP55C was suppressed in a concentration-dependent manner (Fig. 6c, d; $P$ «0.05) while that with SNP55T was not (Fig. 6d).

Thus, NFkB p50 appeared to affect MDM2-P2 promoter activity, resulting in ASE of MDM2.

\section{Subcellular localization of NFKB p50 in ASE-positive and -negative endometrial cancer tissues}

NFKB proteins translocate from the cytoplasm to nucleus and exert transcriptional activity. The p50 factor can form a heterodimer with the $\mathrm{NF}_{\kappa} \mathrm{B} / \mathrm{Rel}$ family member p65, and the p50-p65 complex then functions as a transcriptional activator. However, p50 can also form a p50-p50 homodimer, complex that acts as a transcriptional repressor. Therefore, we attempted to confirm the subcellular localization of $\mathrm{NF}_{k} \mathrm{~B}$ p50 and p65 in two ASE-positive and two ASE-negative endometrial cancer specimens by immunohistochemistry. Although we failed to identify a nuclear localization for p50 in ASE-negative endometrial cancer samples (Fig. 7h, k), NFkB p50 localized to the nucleus in ASE-positive 
Table 3 Histological classification and genotype of endometrial cancer (EMCA) samples

\begin{tabular}{|c|c|c|c|c|c|c|}
\hline & Age & $\begin{array}{l}\text { Histological classification } \\
\text { (grade) }\end{array}$ & $\begin{array}{l}\text { Exon } 1 \text { marker SNP } \\
\text { (rs937283) }\end{array}$ & $\begin{array}{l}\text { 3' UTR marker SNP } \\
\text { (rs1690916) }\end{array}$ & $\begin{array}{l}\text { SNP55 } \\
\text { (rs2870820) }\end{array}$ & $\begin{array}{l}\text { SNP309 } \\
\text { (rs2279744 }\end{array}$ \\
\hline EMCA-1 & 53 & $\begin{array}{l}\text { Endometrioid(G1) } \\
+ \text { Squamous cell }\end{array}$ & $A / G$ & $\mathrm{~A} / \mathrm{G}$ & $\mathrm{C} / \mathrm{T}$ & $T / G$ \\
\hline EMCA-2 & 80 & Endometrioid(G3) & A & G & C & G \\
\hline EMCA-3 & 50 & $\begin{array}{l}\text { Endometrioid(G2) } \\
+ \text { Squamous cell }\end{array}$ & $A / G$ & $A / G$ & $\mathrm{C} / \mathrm{T}$ & $\mathrm{T}$ \\
\hline EMCA-4 & 51 & Serous & $A / G$ & $A / G$ & $\mathrm{C} / \mathrm{T}$ & $\mathrm{T}$ \\
\hline EMCA-5 & 71 & Endometrioid(G1) & G & A & $\mathrm{T}$ & $\mathrm{T}$ \\
\hline EMCA-6 & 74 & Serous & G & G & $\mathrm{C} / \mathrm{T}$ & $\mathrm{T}$ \\
\hline EMCA-7 & 76 & Mixed + Serous & $\mathrm{A} / \mathrm{G}$ & $A / G$ & $\mathrm{C} / \mathrm{T}$ & $\mathrm{T}$ \\
\hline EMCA-8 & 42 & Endometrioid(G1) & A & G & C & $\mathrm{T} / \mathrm{G}$ \\
\hline EMCA-9 & 58 & Endometrioid(G1) & A & G & C & G \\
\hline EMCA-10 & 54 & Endometrioid(G3) & $A / G$ & $A / G$ & $\mathrm{C} / \mathrm{T}$ & $\mathrm{T} / \mathrm{G}$ \\
\hline EMCA-11 & 39 & Endometrioid(G1) & $A / G$ & $A / G$ & $\mathrm{C} / \mathrm{T}$ & $\mathrm{T} / \mathrm{G}$ \\
\hline EMCA-12 & 62 & Endometrioid(G2) & $\mathrm{A} / \mathrm{G}$ & $A / G$ & $\mathrm{C} / \mathrm{T}$ & $\mathrm{T}$ \\
\hline EMCA-13 & 71 & Hetero & G & A & $\mathrm{T}$ & $\mathrm{T}$ \\
\hline EMCA-14 & 66 & Endometrioid(G2) & A & G & C & G \\
\hline EMCA-15 & 81 & Serous & A & G & C & $T / G$ \\
\hline EMCA-16 & 37 & Endometrioid(G1) & A & G & C & G \\
\hline EMCA-17 & 70 & Endometrioid(G1) & $A / G$ & $\mathrm{~A} / \mathrm{G}$ & $C / T$ & $T / G$ \\
\hline EMCA-18 & 43 & Endometrioid(G1) & G & A & $\mathrm{T}$ & $\mathrm{T}$ \\
\hline EMCA-19 & 61 & Serous & $\mathrm{A} / \mathrm{G}$ & $A / G$ & $\mathrm{C} / \mathrm{T}$ & $T / G$ \\
\hline EMCA-20 & 77 & Endometrioid(G2) & $\mathrm{A} / \mathrm{G}$ & $A / G$ & $C / T$ & $T / G$ \\
\hline EMCA-21 & 74 & Endometrioid(G1) & A & G & C & G \\
\hline EMCA-22 & 56 & Endometrioid(G2) & $A / G$ & $A / G$ & $\mathrm{C} / \mathrm{T}$ & $\mathrm{T} / \mathrm{G}$ \\
\hline EMCA-23 & 42 & Endometrioid(G1) & A & G & C & G \\
\hline EMCA-24 & 55 & Endometrioid(G1) & $A / G$ & $A / G$ & $\mathrm{C} / \mathrm{T}$ & $\mathrm{T} / \mathrm{G}$ \\
\hline EMCA-25 & 69 & Endometrioid(G1) & $\mathrm{A} / \mathrm{G}$ & $A / G$ & $\mathrm{C} / \mathrm{T}$ & $T / G$ \\
\hline EMCA-26 & 65 & Endometrioid(G1) & A & G & C & $T / G$ \\
\hline EMCA-27 & 56 & Endometrioid(G2) & $\mathrm{A} / \mathrm{G}$ & $A / G$ & $\mathrm{C} / \mathrm{T}$ & $\mathrm{T}$ \\
\hline EMCA-28 & 83 & Endometrioid(G2) & A & G & C & G \\
\hline EMCA-29 & 58 & Endometrioid(G2) & A & G & C & $\mathrm{T}$ \\
\hline EMCA-30 & 78 & Serous & $A / G$ & $A / G$ & $C / T$ & $T / G$ \\
\hline EMCA-31 & 74 & Endometrioid(G1) & A & G & C & G \\
\hline EMCA-32 & 35 & Endometrioid(G1) & $\mathrm{A} / \mathrm{G}$ & $\mathrm{A} / \mathrm{G}$ & $\mathrm{C} / \mathrm{T}$ & $T / G$ \\
\hline EMCA-33 & 57 & Endometrioid(G1) & $A / G$ & $A / G$ & $\mathrm{C} / \mathrm{T}$ & $\mathrm{T} / \mathrm{G}$ \\
\hline EMCA-34 & 52 & $\begin{array}{l}\text { Endometrioid(G3) } \\
+ \text { Clear cell }\end{array}$ & $\mathrm{A} / \mathrm{G}$ & $\mathrm{A} / \mathrm{G}$ & $\mathrm{C} / \mathrm{T}$ & $\mathrm{T} / \mathrm{G}$ \\
\hline EMCA-35 & 55 & Endometrioid(G2) & G & A & $\mathrm{T}$ & $\mathrm{T}$ \\
\hline EMCA-36 & 49 & Endometrioid(G2) & A & G & C & $\mathrm{T} / \mathrm{G}$ \\
\hline EMCA-37 & 60 & Endometrioid(G1) & A & G & C & G \\
\hline EMCA-38 & 56 & Endometrioid(G3) & A & G & $\mathrm{C} / \mathrm{T}$ & $T / G$ \\
\hline EMCA-39 & 60 & Endometrioid(G1) & G & A & $\mathrm{T}$ & $\mathrm{T}$ \\
\hline
\end{tabular}


Table 3 Histological classification and genotype of endometrial cancer (EMCA) samples (Continued)

\begin{tabular}{|c|c|c|c|c|c|c|}
\hline EMCA-40 & 64 & Endometrioid(G1) & $A / G$ & $\mathrm{~A} / \mathrm{G}$ & $\mathrm{C} / \mathrm{T}$ & $\mathrm{T} / \mathrm{G}$ \\
\hline EMCA-41 & 60 & Endometrioid(G2) & G & A & $T$ & $T$ \\
\hline EMCA-42 & 48 & Endometrioid(G1) & A & G & C & G \\
\hline EMCA-43 & 58 & Clear cell & A & G & C & $\mathrm{T} / \mathrm{G}$ \\
\hline EMCA-44 & 58 & Clear cell & A & G & C & $\mathrm{T} / \mathrm{G}$ \\
\hline EMCA-45 & 55 & Endometrioid(G1) & $A / G$ & $\mathrm{~A} / \mathrm{G}$ & $\mathrm{C} / \mathrm{T}$ & $\mathrm{T}$ \\
\hline
\end{tabular}

samples (Fig. 7b, e); however, p65 did not (Fig. 7c, f). These data indicate that NFKB p50 may have a central role in the ASE of MDM2 in endometrial cancer.

\section{Discussion}

$M D M 2$, one of the most investigated proto-oncogene, plays an important role in tumorigenesis. For a long time, many investigators have attempted to reveal an association between MDM2-overexpression, amplification, or genetic variation and increased cancer risk. Ever since the first report by Bond et al. [28], many casecontrol studies have looked into the roles of SNP309 of MDM2 in various diseases, particularly cancer, including endometrial cancer. However, the association between endometrial cancer risk and the MDM2-SNP309 polymorphism remains controversial.

Our group had previously doubt the association between the status of SNP309 only and endometrial cancer risk [66]. This corresponded to our expectation that the SNP309 status may not affect the transcriptional activity of the MDM2-P2 promoter. We also demonstrated that the Ras /ER/MDM2 pathway was critical for NIH3T3 cell line transformation and the blockage of this pathway resulted in an inhibitory effect in estrogendepended gynecological cancers such as ovarian cancer and endometrial cancer [69-71]. This indicated that MDM2 is critical to the development of endometrial cancer. Several studies have attempted to demonstrate the molecular mechanism of the promoter activity of MDM2-P2 [28, 30, 72]. These studies conducted by in vitro experimentation, because of the difficulty in measuring a quantitative difference in RNA transcription between paternal and maternal alleles. Therefore, it remained unclear whether the phenomenon truly existed in vivo.

We overcame this problem by utilizing PLACE-SSCP with genomic DNA and RNA prepared from the same clinical samples at the same time. PLACE-SSCP is based on technology developed for precise estimation of SNP-allele frequencies in pooled DNA [67]. We could not detect quantitative differences in transcription beyond $20 \%$, between the two alleles in all 23 cancer-free endometria analyzed; however, 17 were heterozygous in SNP309.

Two of the other 17 heterozygous samples showed more than $20 \%$ differences in the total mRNA quantity between two alleles in $M D M 2$, but none had such transcriptional quantitative differences from the MDM2-P1 promoter. Moreover, there were no genetic variations, such as SNPs or microdeletions, to affect the binding affinity of microRNA in the 3' UTR of ASE-positive samples. These findings suggest that ASE of MDM2 in endometrial cancer was caused by the MDM2-P2 promoter.

We identified a new functional SNP, SNP55, which appeared to be regulated by $\mathrm{NF}_{\kappa} \mathrm{B}$. Then we examined SNP55 status in both cancer-free endometria and endometrial cancer samples analyzed by genome DNA sequencing, and found no difference between cancerfree endometria and endometrial cancer samples neither for the genotype frequencies, nor allele frequencies. Thus, we could not show the association of SNP55 polymorphism with endometrial cancers. We then determined the haplotype involving SNP55 and SNP309 in cancer-free endometria $(n=45)$, and

Table 4 Genotype and allele frequencies of MDM2 SNP55 and SNP309 in cancer-free endometria and endometrial cancer samples

\begin{tabular}{|c|c|c|c|c|c|c|c|}
\hline \multirow[b]{2}{*}{ SNP55 rs2870820 } & \multicolumn{3}{|l|}{ Genotype } & \multirow[b]{2}{*}{$p$-value } & \multicolumn{2}{|l|}{ Alleles } & \multirow[b]{2}{*}{$p$-value } \\
\hline & $\mathrm{C} / \mathrm{C}$ & $\mathrm{C} / \mathrm{T}$ & $\mathrm{T} / \mathrm{T}$ & & C & $\mathrm{T}$ & \\
\hline Cancer-free endometrial $(n=45)$ & $17(37.8 \%)$ & $24(53.3 \%)$ & $4(8.9 \%)$ & & $58(64.4 \%)$ & $32(35.6 \%)$ & \\
\hline Endometrial cancer (EMCA) $(n=45)$ & $17(37.8 \%)$ & $22(48.9 \%)$ & $6(13.3 \%)$ & 0.87 & $56(62.2 \%)$ & $34(37.8 \%)$ & 0.88 \\
\hline SNP309 rs2279744 & $\mathrm{T} / \mathrm{T}$ & $\mathrm{T} / \mathrm{G}$ & $\mathrm{G} / \mathrm{G}$ & $p$-value & $\mathrm{T}$ & G & $p$-value \\
\hline Cancer-free endometrial $(n=45)$ & $12(26.7 \%)$ & $24(53.3 \%)$ & $9(20.0 \%)$ & & $48(53.3 \%)$ & $42(46.7 \%)$ & \\
\hline Endometrial cancer (EMCA) $(n=45)$ & $14(31.1 \%)$ & $21(46.7 \%)$ & $10(22.2 \%)$ & 0.85 & $49(54.4 \%)$ & $41(45.5 \%)$ & 1.00 \\
\hline
\end{tabular}



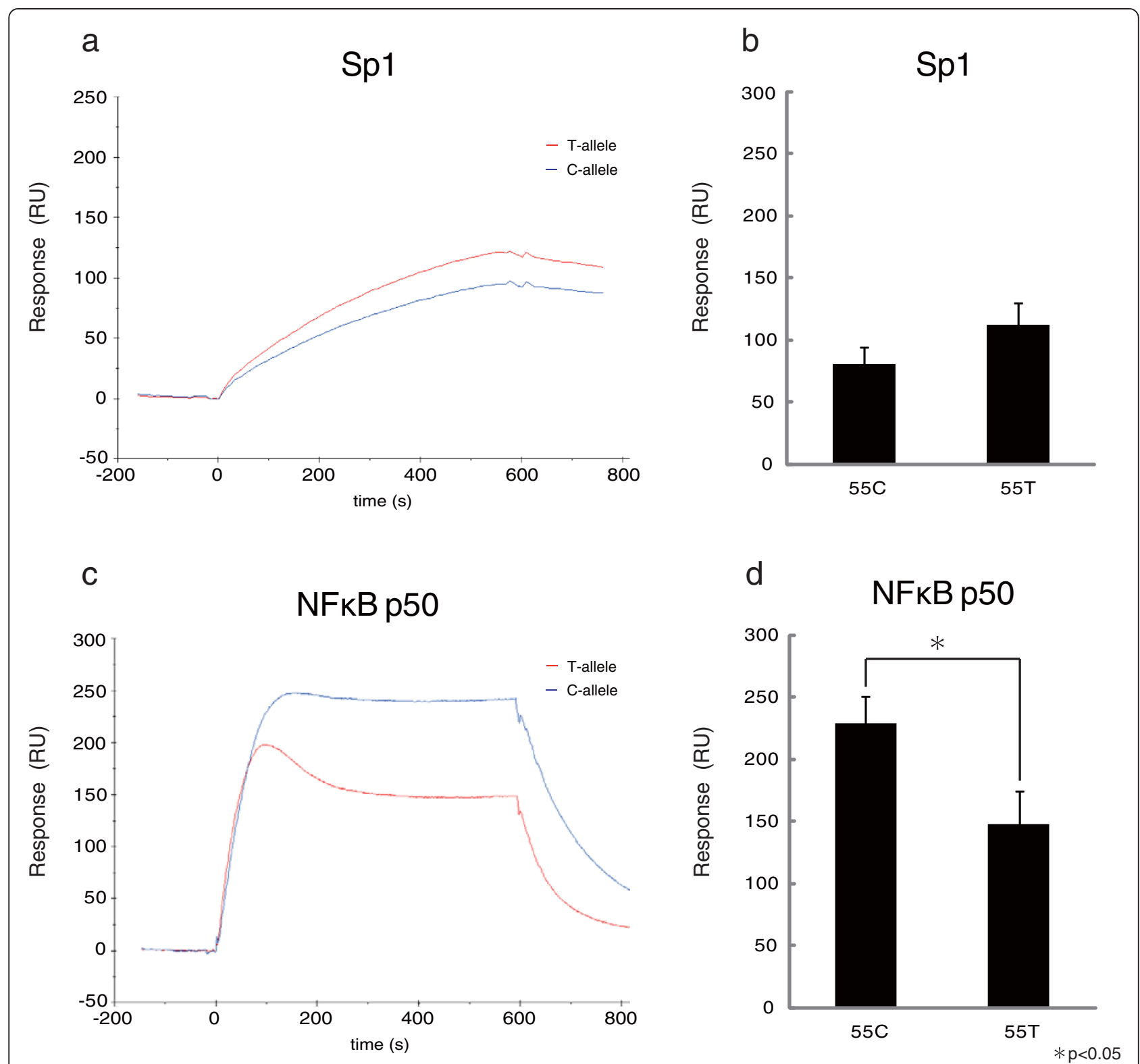

Fig. 5 Biomolecular interaction analysis (BIA) using Biacore. a Biosensor figure of relative quantitative response with transcription factor Sp1, purified from HeLa cells. b Comparison of a response unit (RU) value at 600 s for (a). c Biosensor figure of the relative quantitative response with recombinant nuclear factor kappa-B (NFKB) p50. d Comparison of the RU value at 600 s for (c)

assessed linkage disequilibrium. These two SNPs were in moderate-linkage disequilibrium with each other $\left(r^{2}=0.483\right)$.

We expected that both SNP55 status and transcription factor activity may affect on promoter transcriptional activity, and result in allelic expression differences. As expected, two ASE-positive endometrial cancer samples presented nuclear localization of $\mathrm{NF}_{\mathrm{K}} \mathrm{B}$ p50 observed by immunohistochemistry, although two ASE-negative endometrial cancer samples did not. We attempted to find a quantitative difference in MDM2 protein levels, but failed to detect any difference (data not shown). This was probably because the SNP55 status and NFkB p50 activity were dependent only on P2 promoter activity even though MDM2 was produced from mRNAs transcribed from both $\mathrm{P} 1$ and $\mathrm{P} 2$ promoters.

$\mathrm{NFKB}$ is a transcription factor that is important to various physiological processes, particularly inflammation. The NFkB family comprises five members, p50, p52, p65 (Rel A), c-Rel, and RelB, which form homodimers or heterodimers with each other. These proteins share the highly conserved region, the Rel homology domain, which 


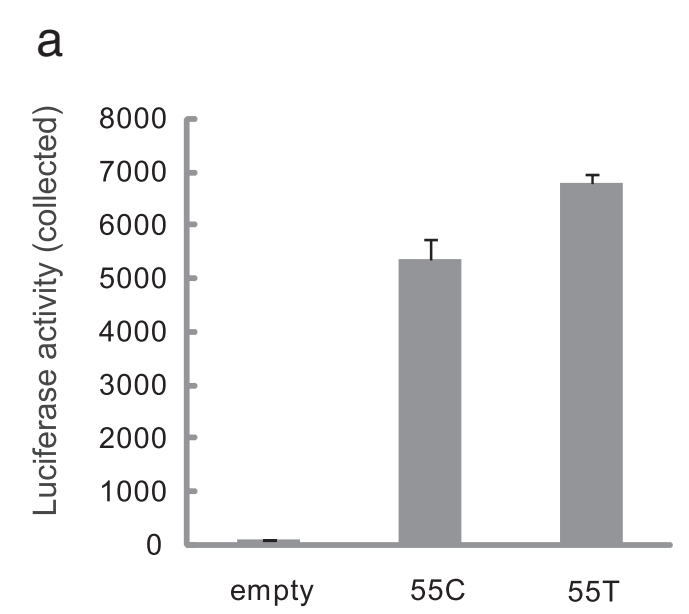

C

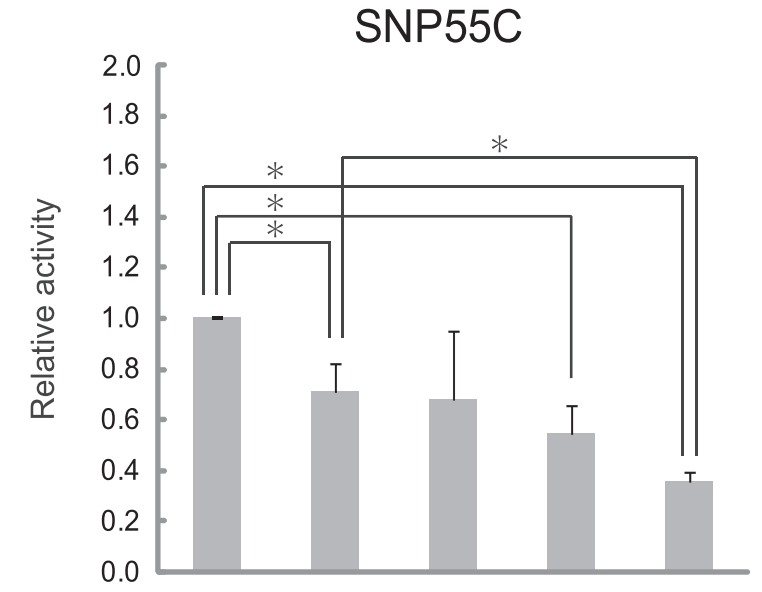

myc-Sp1

FLAG-p50

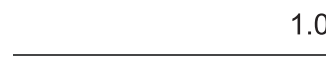

\begin{abstract}
.0
\end{abstract}
$(\mu \mathrm{g})$

$(\mu \mathrm{g})$

b

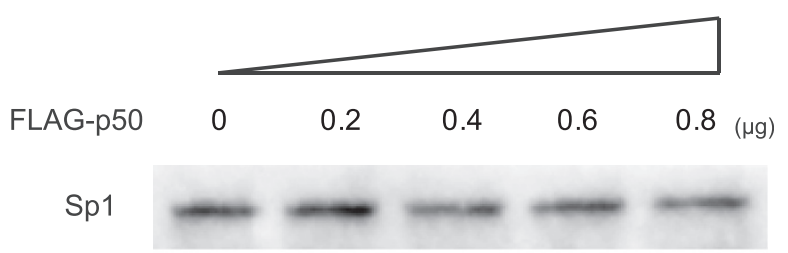

NFkB-p50

GAPDH

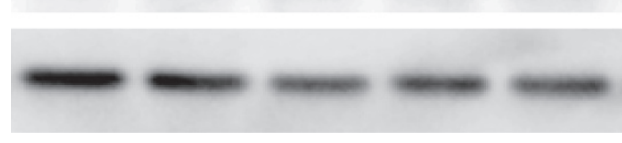

d

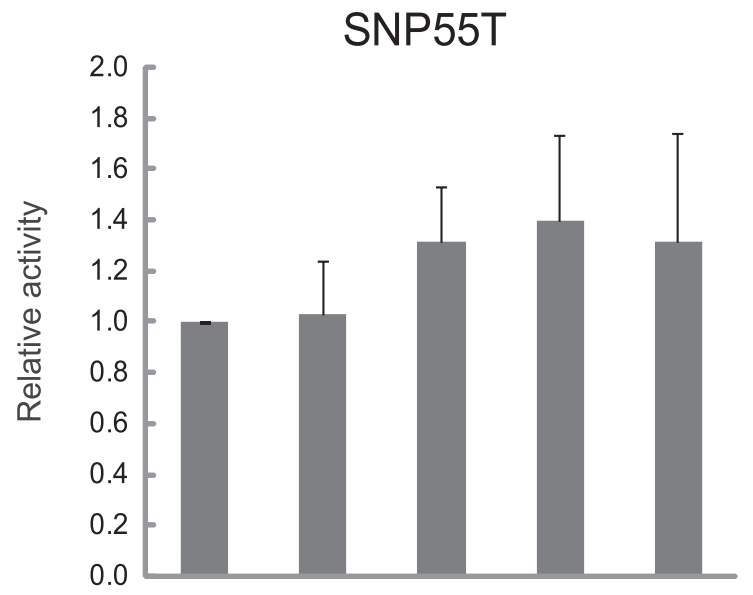

myc-Sp1

1.0

$(\mu \mathrm{g})$

$\begin{array}{llllll}\text { FLAG-p50 } & 0 & 0.2 & 0.4 & 0.6^{0} & 0.8_{(\mu \mathrm{g})}\end{array}$

Fig. 6 The effect of SNP55 on MDM2-P2 promoter activity. a The pGL4 luciferase reporter plasmids containing either SNP55T or SNP55C were co-transfected with pcDNA-LacZ (control) and pcDNA-Sp1 (N-terminus myc-tagged). b Western blot analysis confirming a gradient increase of nuclear factor kappa-B (NFKB) p50. Glyceraldehyde 3-phosphate dehydrogenase (GAPDH) is shown as an internal control. c The amount of pcDNA- nuclear factor kappa-B (NFkB) p50 (0-0.8 $\mu \mathrm{g})$ was gradually increased and co-transfected with the SNP55C reporter plasmid. d The amount of pcDNA- nuclear factor kappa-B (NFkB) p50 (0-0.8 $\mu \mathrm{g})$ was gradually increased and co-transfected with the SNP55T reporter plasmid

is essential for DNA binding. Only p65, c-Rel, and RelB have a transcriptional activation domain. Because the others lack such a domain, the p50-p50 complex acts as a transcriptional repressor [73]. Although activation of the p65-p50 complex has been intensively investigated, the mechanisms of p50 production, homodimer formation, nuclear translocation, and activation still need to be determined [74]. Hirano et al., showed functional interference between transcription factor Sp1 and the p50 homodimer at the same DNA binding site [68], same as our observation.

\section{Conclusions}

In this study, we identified a new functional SNP on the MDM2-P2 promoter, SNP55. We then demonstrated the MDM2-P2 promoter was regulated by both transcription factors Sp1 and p50, and that the p50 homodimer suppressed MDM2-P2 promoter activity through the transcription factor Sp1/NFkB binding site including SNP55. These findings suggest that both genetic variations and transcription factor activity affect $M D M 2$ activation in endometrial cancer. Given that $M D M 2$ appears to play a critical role in endometrial cancer, control of $\mathrm{NF \kappa B}$ p50 


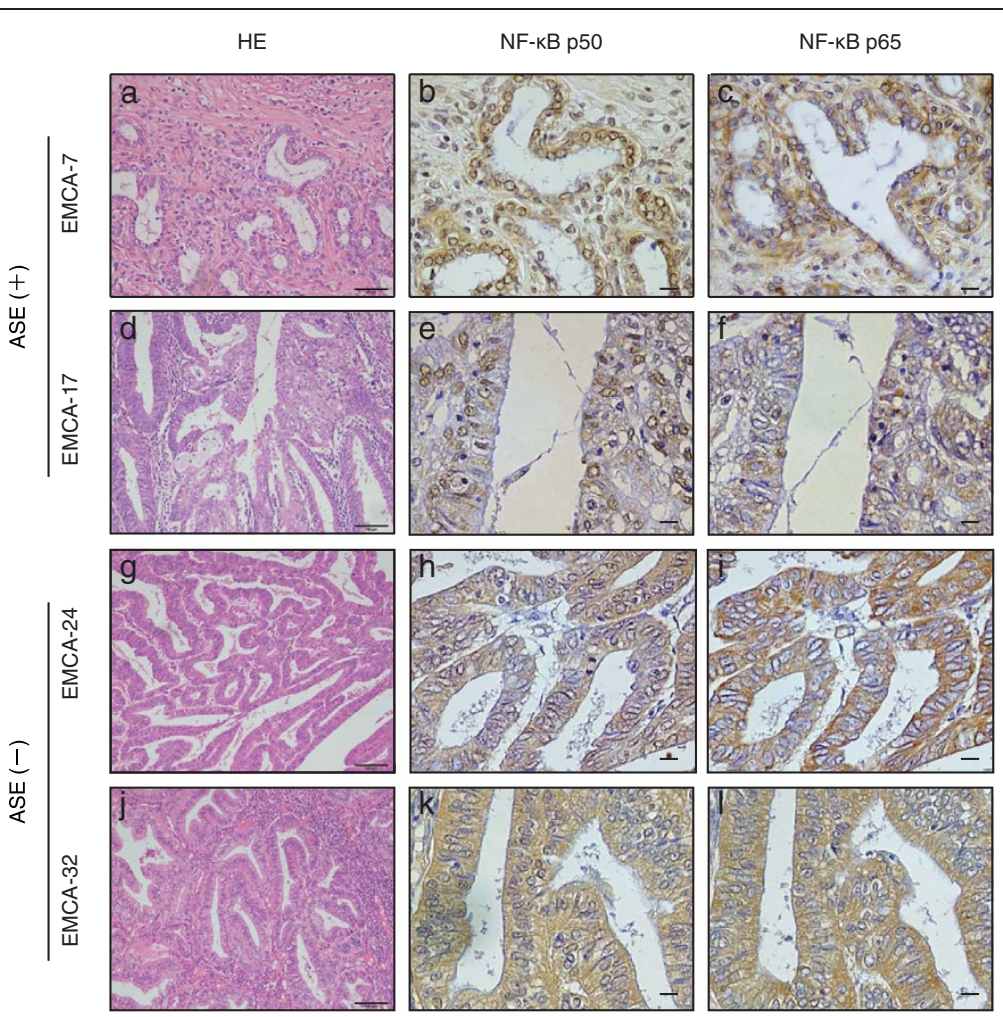

Fig. 7 Immunohistochemistry of cancer-free endometrial and endometrial cancer samples. Hematoxylin eosin staining (a, $\mathbf{d}, \mathbf{g}$, and $\mathbf{j})$ and immunohistochemical staining of NFKB p65 (c, $\mathbf{f}, \mathbf{i}$, and $\mathbf{I})$ and NFKB p50 (b, e, h, and $\mathbf{k}$ ) in four endometrial cancer samples $[T w o$ were allele-specific expression (ASE) positive $(+)$; the others were ASE negative $(-)$ ]. Scale bar $=50 \mu \mathrm{m}$

homodimer provides the possibility for a new therapeutic target.

\section{Abbreviations}

SNP: Single nucleotide polymorphism; ASE: Allele-specific expression; NFkB: Nuclear factor kappa-B; BIA: Biomolecular interaction analysis; PLACE-SSCP: Post-labeling followed by automated capillary electrophoresis under single-strand conformation polymorphism conditions.

\section{Competing interests}

The authors declare that they have no competing interests.

\section{Authors' contributions}

$\mathrm{KO}$ designed and performed experiments, analyzed data and wrote the manuscript. RT assisted with experiments and reviewed the manuscripts. KH and TT participated in PLACE-SSCP analysis. KS and TY procured tissue samples. KA and HY provided technical advices. KK supervised the project and provided critical review of the manuscript. All authors read and approved the final manuscript.

\section{Acknowledgements}

This work was supported by Grants-in-Aid from the Ministry of Education, Culture, Sports, Science and Technology, Japan (Grant numbers 23249075 and 23791847).

\section{Author details}

${ }^{1}$ Department of Obstetrics and Gynecology, Graduate School of Medical Sciences, Kyushu University, 3-1-1 Maidashi, Higashi-ku, Fukuoka 812-8582, Japan. ${ }^{2}$ Research Center for Environmental Medical Sciences, Kyushu University, Fukuoka, Japan. ${ }^{3}$ Division of Genome Analysis, Research Center for Genetic Information, Medical Institute of Bioregulation, Kyushu University,
Fukuoka, Japan. ${ }^{4}$ Innovation Center for Medical Redox Navigation, Kyushu University, Fukuoka, Japan. ${ }^{5}$ Current address: Department of Obstetrics and Gynecology, National Hospital Organization Ibusuki Medical Center, 4145, Junicho, Ibusuki, Kagoshima 891-0498, Japan.

\section{Received: 8 September 2014 Accepted: 13 August 2015}

Published online: 21 August 2015

\section{References}

1. Adams PD. Healing and hurting: molecular mechanisms, functions, and pathologies of cellular senescence. Mol Cell. 2009;36(1):2-14.

2. Collado M, Serrano M. Senescence in tumours: evidence from mice and humans. Nat Rev Cancer. 2010;10(1):51-7.

3. Rodier F, Campisi J. Four faces of cellular senescence. J Cell Biol. 2011;192(4):547-56.

4. Reddel RR. The role of senescence and immortalization in carcinogenesis. Carcinogenesis. 2000;21(3):477-84.

5. Shay JW, Wright WE. Senescence and immortalization: role of telomeres and telomerase. Carcinogenesis. 2005;26(5):867-74.

6. Lleonart ME, Artero-Castro A, Kondoh H. Senescence induction; a possible cancer therapy. Mol Cancer. 2009;8:3.

7. Tan P. Germline polymorphisms as modulators of cancer phenotypes. BMC Med. 2008;6:27.

8. Johnson NA, Porter AH. Rapid speciation via parallel, directional selection on regulatory genetic pathways. J Theor Biol. 2000;205(4):527-42.

9. Yan H, Dobbie Z, Gruber SB, Markowitz S, Romans K, Giardiello FM, et al. Small changes in expression affect predisposition to tumorigenesis. Nat Genet. 2002;30(1):25-6.

10. Hindorff LA, Sethupathy P, Junkins HA, Ramos EM, Mehta JP, Collins FS, et al. Potential etiologic and functional implications of genome-wide association loci for human diseases and traits. Proc Natl Acad Sci U S A. 2009;106(23):9362-7. 
11. Manolio TA, Collins FS. The HapMap and genome-wide association studies in diagnosis and therapy. Annu Rev Med. 2009;60:443-56.

12. Yan H, Yuan W, Velculescu VE, Vogelstein B, Kinzler KW. Allelic variation in human gene expression. Science (New York, NY). 2002;297(5584):1143.

13. Knight JC. Allele-specific gene expression uncovered. Trends Gen. 2004;20(3):113-6.

14. Pastinen T. Genome-wide allele-specific analysis: insights into regulatory variation. Nat Rev Genet. 2010;11(8):533-8.

15. Buckland PR. Allele-specific gene expression differences in humans. Hum Mol Genet. 2004;13 Spec No 2:R255-60.

16. Lee MP. Allele-specific gene expression and epigenetic modifications and their application to understanding inheritance and cancer. Biochim Biophys Acta. 2012;1819(7):739-42.

17. Lo HS, Wang Z, Hu Y, Yang HH, Gere S, Buetow KH, et al. Allelic variation in gene expression is common in the human genome. Genome Res. 2003;13(8):1855-62.

18. Hoogendoorn B, Coleman SL, Guy CA, Smith K, Bowen T, Buckland PR, et al. Functional analysis of human promoter polymorphisms. Hum Mol Genet. 2003;12(18):2249-54

19. Pant PV, Tao H, Beilharz EJ, Ballinger DG, Cox DR, Frazer KA. Analysis of allelic differential expression in human white blood cells. Genome Res. 2006;16(3):331-9.

20. Heap GA, Yang JH, Downes K, Healy BC, Hunt KA, Bockett N, et al. Genome-wide analysis of allelic expression imbalance in human primary cells by high-throughput transcriptome resequencing. Hum Mol Genet. 2010;19(1):122-34

21. Valle L, Serena-Acedo T, Liyanarachchi S, Hampel H, Comeras I, Li Z, et al. Germline allele-specific expression of TGFBR1 confers an increased risk of colorectal cancer. Science (New York, NY). 2008;321(5894):1361-5.

22. Abdollahi MR, Lewis RM, Gaunt TR, Cumming DV, Rodriguez S, Rose-Zerilli M, et al. Quantitated transcript haplotypes (QTH) of AGTR1, reduced abundance of mRNA haplotypes containing 1166C (rs5186:A > C), and relevance to metabolic syndrome traits. Hum Mutat. 2007;28(4):365-73.

23. Grigorova M, Punab M, Poolamets $\mathrm{O}$, Kelgo P, Ausmees K, Korrovits P, et al, Increased Prevalance of the $-211 \mathrm{~T}$ allele of follicle stimulating hormone (FSH) beta subunit promoter polymorphism and lower serum FSH in infertile men. J Clin Endocrinol Metabol. 2010;95(1):100-8.

24. Grigorova M, Punab M, Ausmees K, Laan M. FSHB promoter polymorphism within evolutionary conserved element is associated with serum FSH level in men. Hum Reprod. 2008;23(9):2160-6.

25. Chen X, Weaver J, Bove BA, Vanderveer LA, Weil SC, Miron A, et al. Allelic imbalance in BRCA1 and BRCA2 gene expression is associated with an increased breast cancer risk. Hum Mol Genet. 2008;17(9):1336-48.

26. Popat S, Stone J, Houlston RS. Allelic imbalance in colorectal cancer at the CRAC1 locus in early-onset colorectal cancer. Cancer Genet Cytogenet. 2003; 145(1):70-3.

27. Pinheiro H, Bordeira-Carrico R, Seixas S, Carvalho J, Senz J, Oliveira P, et al. Allele-specific $\mathrm{CDH} 1$ downregulation and hereditary diffuse gastric cancer. Hum Mol Genet. 2010;19(5):943-52.

28. Bond GL, Hu W, Bond EE, Robins H, Lutzker SG, Arva NC, et al. A single nucleotide polymorphism in the MDM2 promoter attenuates the p53 tumor suppressor pathway and accelerates tumor formation in humans. Cell. 2004;119(5):591-602

29. Wang M, Zhang Z, Zhu H, Fu G, Wang S, Wu D, et al. A novel functional polymorphism C1797G in the MDM2 promoter is associated with risk of bladder cancer in a Chinese population. Clin Cancer Res. 2008;14(11):3633-40.

30. Knappskog S, Bjornslett M, Myklebust LM, Huijts PE, Vreeswijk MP, Edvardsen $\mathrm{H}$, et al. The MDM2 promoter SNP285C/309G haplotype diminishes Sp1 transcription factor binding and reduces risk for breast and ovarian cancer in Caucasians. Cancer Cell. 2011;19(2):273-82.

31. Fakharzadeh SS, Trusko SP, George DL. Tumorigenic potential associated with enhanced expression of a gene that is amplified in a mouse tumor cell line. EMBO J. 1991;10(6):1565-9.

32. Piette J, Neel H, Marechal V. Mdm2: keeping p53 under control. Oncogene. 1997;15(9):1001-10.

33. Momand J, Wu HH, Dasgupta G. MDM2-master regulator of the p53 tumor suppressor protein. Gene. 2000;242(1-2):15-29.

34. Juven-Gershon T, Oren M. Mdm2: the ups and downs. Mol Med. 1999;5(2):71-83

35. Michael D, Oren M. The p53-Mdm2 module and the ubiquitin system. Semin Cancer Biol. 2003;13(1):49-58
36. Oliner JD, Kinzler KW, Meltzer PS, George DL, Vogelstein B. Amplification of a gene encoding a p53-associated protein in human sarcomas. Nature. 1992;358(6381):80-3

37. Leach FS, Tokino T, Meltzer P, Burrell M, Oliner JD, Smith S, et al. p53 Mutation and MDM2 amplification in human soft tissue sarcomas. Cancer Res. 1993;53(10 Suppl):2231-4.

38. Momand J, Jung D, Wilczynski S, Niland J. The MDM2 gene amplification database. Nucleic Acids Res. 1998;26(15):3453-9.

39. Bueso-Ramos CE, Yang Y, de Leon E, McCown P, Stass SA, Albitar M. The human MDM-2 oncogene is overexpressed in leukemias. Blood. 1993;82(9):2617-23.

40. Polsky D, Bastian BC, Hazan C, Melzer K, Pack J, Houghton A, et al. HDM2 protein overexpression, but not gene amplification, is related to tumorigenesis of cutaneous melanoma. Cancer Res. 2001;61(20):7642-6.

41. Polsky D, Melzer K, Hazan C, Panageas KS, Busam K, Drobnjak M, et al. HDM2 protein overexpression and prognosis in primary malignant melanoma. J Natl Cancer Inst. 2002;94(23):1803-6.

42. Lukas J, Gao DQ, Keshmeshian M, Wen WH, Tsao-Wei D, Rosenberg S, et al. Alternative and aberrant messenger RNA splicing of the mdm2 oncogene in invasive breast cancer. Cancer Res. 2001;61(7):3212-9.

43. Hori M, Shimazaki J, Inagawa S, Itabashi M. Overexpression of MDM2 oncoprotein correlates with possession of estrogen receptor alpha and lack of MDM2 mRNA splice variants in human breast cancer. Breast Cancer Res Treat. 2002;71(1):77-83.

44. Juven T, Barak Y, Zauberman A, George DL, Oren M. Wild type p53 can mediate sequence-specific transactivation of an internal promoter within the mdm2 gene. Oncogene. 1993;8(12):3411-6.

45. Wu X, Bayle JH, Olson D, Levine AJ. The p53-mdm-2 autoregulatory feedback loop. Genes Dev. 1993;7(7A):1126-32.

46. Zauberman A, Flusberg D, Haupt Y, Barak Y, Oren M. A functional p53responsive intronic promoter is contained within the human mdm2 gene. Nucleic Acids Res. 1995;23(14):2584-92.

47. Knappskog S, Trovik J, Marcickiewicz J, Tingulstad S, Staff AC, Romundstad P, et al. SNP285C modulates oestrogen receptor/Sp1 binding to the MDM2 promoter and reduces the risk of endometrial but not prostatic cancer. Eur J Cancer (Oxford, England: 1990). 2012;48(13):1988-96.

48. Knappskog S, Lonning PE. MDM2 promoter SNP285 and SNP309; phylogeny and impact on cancer risk. Oncotarget. 2011;2(3):251-8.

49. Bond $\mathrm{GL}, \mathrm{Hu}$ W, Levine A. A single nucleotide polymorphism in the MDM2 gene: from a molecular and cellular explanation to clinical effect. Cancer Res. 2005;65(13):5481-4.

50. Knappskog S, Gansmo LB, Romundstad P, Bjornslett M, Trovik J, SommerfeltPettersen J, et al. MDM2 promoter SNP344T > A (rs1196333) status does not affect cancer risk. PLOS ONE. 2012;7(4), e36263.

51. Walsh CS, Miller CW, Karlan BY, Koeffler HP. Association between a functional single nucleotide polymorphism in the MDM2 gene and sporadic endometrial cancer risk. Gynecol Oncol. 2007;104(3):660-4.

52. Ohmiya N, Taguchi A, Mabuchi N, Itoh A, Hirooka Y, Niwa Y, et al. MDM2 promoter polymorphism is associated with both an increased susceptibility to gastric carcinoma and poor prognosis. J Clin Oncol. 2006;24(27):4434-40.

53. Onat OE, Tez M, Ozcelik T, Toruner GA. MDM2 T309G polymorphism is associated with bladder cancer. Anticancer Res. 2006;26(5A):3473-5.

54. Post SM, Pant V, Abbas H, Quintas-Cardama A. Prognostic impact of the MDM2SNP309 allele in leukemia and lymphoma. Oncotarget. 2010;1(3):168-74.

55. Paulin FE, O'Neill M, McGregor G, Cassidy A, Ashfield A, Ali CW, et al. MDM2 SNP309 is associated with high grade node positive breast tumours and is in linkage disequilibrium with a novel MDM2 intron 1 polymorphism. BMC Cancer. 2008;8:281

56. Wo X, Han D, Sun H, Liu Y, Meng X, Bai J, et al. MDM2 SNP309 contributes to tumor susceptibility: a meta-analysis. J Gen Genomics $=$ Yi chuan Xue bao. 2011;38(8):341-50.

57. El Hallani S, Marie Y, Idbaih A, Rodero M, Boisselier B, Laigle-Donadey F, et al. No association of MDM2 SNP309 with risk of glioblastoma and prognosis. J Neuro-Oncol. 2007;85(3):241-4.

58. Wilkening $S$, Hemminki K, Rudnai $P$, Gurzau E, Koppova K, Forsti A, et al. No association between MDM2 SNP309 promoter polymorphism and basal cell carcinoma of the skin. Br J Dermatol. 2007;157(2):375-7.

59. Petenkaya A, Bozkurt B, Akilli-Ozturk O, Kaya HS, Gur-Dedeoglu B, Yulug IG. Lack of association between the MDM2-SNP309 polymorphism and breast cancer risk. Anticancer Res. 2006;26(6C):4975-7. 
60. Wilkening S, Bermejo JL, Hemminki K. MDM2 SNP309 and cancer risk: a combined analysis. Carcinogenesis. 2007;28(11):2262-7.

61. Campbell IG, Eccles DM, Choong DY. No association of the MDM2 SNP309 polymorphism with risk of breast or ovarian cancer. Cancer Lett. 2006;240(2):195-7.

62. Terry K, McGrath M, Lee IM, Buring J, De Vivo I. MDM2 SNP309 is associated with endometrial cancer risk. Cancer Epidemiol Biomark Prev. 2008;17(4):983-6.

63. Ueda M, Yamamoto M, Nunobiki O, Toji E, Sato N, Izuma S, et al. Murine double-minute 2 homolog single nucleotide polymorphism 309 and the risk of gynecologic cancer. Hum Cell. 2009;22(2):49-54.

64. Li Y, Zhao H, Sun L, Huang L, Yang Q, Kong B. MDM2 SNP309 is associated with endometrial cancer susceptibility: a meta-analysis. Hum Cell. 2011;24(2):57-64.

65. Zajac A, Stachowiak G, Pertynski T, Romanowicz H, Wilczynski J, Smolarz B. Association between MDM2 SNP309 polymorphism and endometrial cancer risk in Polish women. Pol J Pathol. 2012;63(4):278-83.

66. Yoneda T, Kuboyama A, Kato K, Ohgami T, Okamoto K, Saito T, et al. Association of MDM2 SNP309 and TP53 Arg72Pro polymorphisms with risk of endometrial cancer. Oncol Rep. 2013;30(1):25-34.

67. Tahira T, Kukita Y, Higasa K, Okazaki Y, Yoshinaga A, Hayashi K. Estimation of SNP allele frequencies by SSCP analysis of pooled DNA. Methods Mol Biol (Clifton, NJ). 2009;578:193-207.

68. Hirano F, Tanaka H, Hirano Y, Hiramoto M, Handa H, Makino I, et al. Functional interference of Sp1 and NF-kappaB through the same DNA binding site. Mol Cell Biol. 1998;18(3):1266-74.

69. Kato K, Ueoka Y, Hachiya T, Nishida J, Wake N. Contribution of enhanced transcriptional activation by ER to [12Val] K-Ras mediated NIH3T3 cell transformation. Oncogene. 1997;15(25):3037-46.

70. Kato K, Horiuchi S, Takahashi A, Ueoka Y, Arima T, Matsuda T, et al. Contribution of estrogen receptor alpha to oncogenic K-Ras-mediated $\mathrm{NIH} 3 \mathrm{~T} 3$ cell transformation and its implication for escape from senescence by modulating the p53 pathway. J Biol Chem. 2002;277(13):11217-24.

71. Suga S, Kato K, Ohgami T, Yamayoshi A, Adachi S, Asanoma K, et al. An inhibitory effect on cell proliferation by blockage of the MAPK/estrogen receptor/MDM2 signal pathway in gynecologic cancer. Gynecol Oncol. 2007:105(2):341-50.

72. Post SM, Quintas-Cardama A, Pant V, Iwakuma T, Hamir A, Jackson JG, et al. A high-frequency regulatory polymorphism in the p53 pathway accelerates tumor development. Cancer Cell. 2010;18(3):220-30.

73. Tong X, Yin L, Washington R, Rosenberg DW, Giardina C. The p50-p50 NFkappaB complex as a stimulus-specific repressor of gene activation. Mol Cell Biochem. 2004;265(1-2):171-83.

74. Pereira SG, Oakley F. Nuclear factor-kappaB1: regulation and function. Int J Biochem Cell Biol. 2008;40(8):1425-30.

\section{Submit your next manuscript to BioMed Central and take full advantage of:}

- Convenient online submission

- Thorough peer review

- No space constraints or color figure charges

- Immediate publication on acceptance

- Inclusion in PubMed, CAS, Scopus and Google Scholar

- Research which is freely available for redistribution 